\title{
Vertebral growth modulation by posterior dynamic deformity correction device in skeletally immature patients with moderate adolescent idiopathic scoliosis
}

\author{
Yizhar Floman ${ }^{1} \cdot$ Ron El-Hawary ${ }^{2} \cdot$ Baron S. Lonner $^{3} \cdot$ Randal R. Betz $^{4} \cdot$ Uri Arnin $^{5}$
}

Received: 11 July 2020 / Accepted: 10 August 2020 / Published online: 21 August 2020

(c) The Author(s) 2020

\begin{abstract}
Study design Retrospective, comparative, multicenter.

Introduction Growth modulating spinal implants are used in the management of scoliosis such as anterior vertebral body tethering. A motion-sparing posterior device (PDDC) was recently approved for the treatment of moderate AIS. The purpose of this study was to determine if the PDDC can modulate growth in skeletally immature patients with AIS.

Methods From a database of patients treated with the PDDC over 4 years, we identified those who had a minimum of 2 years follow-up. Pre-operative and post-operative Cobb angles and coronal plane wedging of the apical vertebra were evaluated on standing full length radiographs. Independent sample $t$ test and one-way ANOVA with post-hoc Tukey HSD analysis was used to compare three groups in varying skeletal maturity: Risser 0-1, Risser 2-3, and Risser 4-5.

Results 45 patients (14.2-years old, $11-17)$ were evaluated with a mean pre-op curve of $46^{\circ}\left(35^{\circ}-66^{\circ}\right)$. The average preoperative major curve magnitude, of either Lenke 1 or 5 curve type, was similar among the three groups $47.6^{\circ}, 46^{\circ}$ and $41.5^{\circ}$. Deformity correction was similar in the three groups, with reduction to $26.4^{\circ}, 20.4^{\circ}$ and $26.2^{\circ}$, respectively, at final follow-up [p $<0.05$ ]. Pre-op wedging $7.4^{\circ}\left(3.8^{\circ}-15^{\circ}\right)$ was reduced after surgery to $5.7^{\circ}\left(1^{\circ}-15^{\circ}\right)(p<0.05)$. Of those patients, Risser $0-1(n=16)$ had preoperative wedging of $9.5^{\circ}\left(6^{\circ}-14.5^{\circ}\right)$ that was reduced to $5.4^{\circ}\left(1^{\circ}-8^{\circ}\right)$ postoperatively $(p<0.05)$; Risser $2-3(n=15)$ had pre-op $7.7^{\circ}\left(4^{\circ}-15^{\circ}\right)$ vs. post-op $7.0^{\circ}\left(3^{\circ}-15^{\circ}\right)$; Risser $4-5(n=14)$ had pre-op $4.8^{\circ}\left(3.8^{\circ}-6.5^{\circ}\right)$ vs. post-op $4.7^{\circ}\left(3.7^{\circ}-6.5^{\circ}\right)$. Delta Wedging in Risser 0-1 stage was significantly different than for Risser 2-3 and for Risser 4-5.

Conclusion The posterior dynamic deformity correction device was able to modulate vertebral body wedging in skeletally immature patients with AIS. This was most evident in patients who were Risser 0-1. In contrast, curve correction was similar among the three groups. This finding lends support to the device's ability to modulate growth.
\end{abstract}

Keywords Remodeling $\cdot$ Posterior $\cdot$ Dynamic $\cdot$ Correction $\cdot$ Idiopathic scoliosis

Yizhar Floman

yizharfloman@gmail.com

1 Israel Spine Center, Assuta Hospital, 20 Habarzel, Tel Aviv, Israel

2 Division of Orthopedic Surgery, IWK Health Center, University Ave, PO Box 9700, Halifax, NS 5850 B3K-6R8, Canada

3 Mount Sinai Hospital, 1468 Madison Ave, New York, NY 10029, USA

4 Institute for Spine and Scoliosis, 3100 Princeton Pike, Lawrenceville, NJ, USA

5 ApiFix LTD, Kochav Yokneam Bldg, 1 Hacarmel street, Yokneam Ilit, Israel

\section{Introduction}

Motion sparing and growth modulating spinal implants were recently incorporated into the surgical armamentarium of adolescent idiopathic scoliosis and currently utilize anterior implants such as vertebral body tethering (VBT) $[1,2]$ or vertebral body stapling (VBS) [3, 4]. Although VBT and to a lesser extent VBS, has been reported to promote growth modulation, their implantation necessitates an anterior approach to the spine. Many spine surgeons are less familiar with the anterior route and are more proficient with the posterior approach. A novel posterior dynamic deformity correction device (PDDC) (ApiFix Ltd., Misgav, Israel) was developed to provide a less invasive, motion sparing means to correct single Lenke 1 and 5 AIS curves and control the deformity 
over time [5-7]. The PDDC device has a ratchet mechanism that allows unidirectional elongation of an expandable rod which is made of titanium alloy with amorphous diamondlike ceramic coating. The expandable rod, with polyaxial rings (eye joint) at its extremity, is anchored to the spine with two pedicle screws that are implanted on the concavity of the main curve. The ratchet mechanism enables both immediate intraoperative curve reduction and potential gradual postoperative curve correction by unidirectional device elongation, which is driven by optional corrective spinal exercises performed by the patient. The device may be looked upon as an internal brace not dependent on brace wear compliance. This motion-sparing posterior device has a CE mark and was recently approved in the US by the Federal Drug Administration (FDA) for the treatment of moderate AIS. The ability of PDDC to significantly correct moderate AIS curves in patients fitting the current US indications i.e. $40^{\circ}-60^{\circ}$ single major curves reduced to $\leq 30^{\circ}$ on bending, was recently reported [8]. It was found that in $82 \%$ of the cohort, it was possible to reduce the main curve to $\leq 30^{\circ}$ at 2 years follow-up.

The purpose of this study was to determine if the PDDC can act as a true internal brace and modulate growth in skeletally immature patients with moderate AIS. If proved to significantly reduce the spinal curve and modulate vertebral wedging, it could enable future removal of the "internal brace" implant after skeletal maturity. Preliminary results have been accepted for presentation at the 2020 IMAST meeting [9].

\section{Materials and methods}

From a registry of AIS patients treated with the PDDC (between 2015 and 2018), we identified those who had a minimum of 2 years of radiologic follow-up. As a marker for vertebral body growth modification induced by the altered scoliosis biomechanics, coronal plane wedging of the apical vertebra was evaluated. Two observers independently measured wedging of the apical vertebra on standing full length radiographs taken preoperatively and at final followup. The average of the two measurements was recorded. Independent sample $t$-test and one-way ANOVA with posthoc Tukey HSD analysis was used to compare groups in varying skeletal maturation stages: Risser $0-1$, Risser $2-3$, and Risser 4-5.

We also recorded the preoperative and postoperative Cobb angles of the major instrumented curve at the last follow-up visit.

\section{Results}

From a registry of 220 patients that underwent PDDC surgery, 16 patients that were in a Risser 0-1 stage at the time of operation and had a minimum of 2 year follow-up were identified. In all 16 patients, the triradiate cartilage was closed at the time of surgery. This group was compared to 15 patients that that were in the Risser 2-3 stage and 14 that were in the Risser 4-5 stage at surgery and had a least 2 years of follow-up. The total number of patients evaluated was 45, of which 41 females and 4 males, aged 11-17 years (average 14.2). The indications for surgery were $40^{\circ}-60^{\circ}$ curves, reduced on lateral bending views to $35^{\circ}$ or less with kyphosis not exceeding $55^{\circ}$. Non-compliant braced patients or patients with Lenke 5 curves with Cobb angles $\geq 35^{\circ}$ were also subjected to PDDC surgery. There were 35 patients with Lenke type 1 curves and ten patients with Lenke type 5 curves (Fig. 1). Follow-up ranged from 2-4 years, average 2.3 years. All patients were Risser 4 or 5 at the end of the follow-up period. The cohort had a mean pre-operative major scoliosis curve of $46^{\circ}\left(35^{\circ}-66^{\circ}\right)$. The average preoperative major curve magnitude, of both curve types, was similar among the three Risser groups $47.6^{\circ}, 46^{\circ}$ and $41.5^{\circ}$. Curves were reduced to $26.4^{\circ}, 20.4^{\circ}$ and $26.2^{\circ}$, respectively, at final follow-up [p $<0.05]$. At last follow-up visit thoracic kyphosis increased on average by $7^{\circ}$ in the Lenke 1 curves while lumbar lordosis decreased by $4^{\circ}$ in the Lenke 5 curves. The average pre-operative coronal apical wedging of $7.4^{\circ}\left(3.8^{\circ}-15^{\circ}\right)$ was reduced to $5.7^{\circ}\left(1^{\circ}-15^{\circ}\right)$ at final follow-up $(p<0.05)$ (Table 1). Delta wedging for the entire cohort was $1.7^{\circ}\left(-0.5^{\circ}-9^{\circ}\right)(p<0.05)$. Patients with Risser $0-1$ grading $(n=16)$ had pre-operative wedging of $9.5^{\circ}\left(6^{\circ}-14.5^{\circ}\right)$ compared to wedging of $5.4^{\circ}\left(1^{\circ}-8^{\circ}\right)$ after surgery $(p<0.05)$; Risser $2-3$ patients $(n=15)$ had pre-operative wedging of $7.7^{\circ}\left(4^{\circ}-15^{\circ}\right)$ vs. post-operative wedging of $7.0^{\circ}\left(3^{\circ}-15^{\circ}\right)$; Risser $4-5$ patients $(n=14)$ had pre-operative wedging of $4.8^{\circ}\left(3.8^{\circ}-6.5^{\circ}\right)$ versus post-operative wedging of $4.7^{\circ}\left(3.7^{\circ}-6.5^{\circ}\right)$. The change in wedging before and after surgery was as follows: Risser $0-1=4.1^{\circ}\left(0^{\circ}-9^{\circ}\right)(p<0.05)$; Risser $2-3=0.7^{\circ}\left(0^{\circ}-4^{\circ}\right)$, Risser $4-5=0.1^{\circ}\left(-0.5^{\circ}-1.2^{\circ}\right)$. Delta wedging in Risser $0-1$ patients was significantly different from the delta value for Risser 2-3 and for Risser 4-5 $(p<0.05)$ (Figs. 1 and 2, Table 1).

Four patients underwent revision surgery: One case was converted to VBT as a result of partial screw pull-out. In the other three patients pedicle screw misplacement, nut loosening or ratchet malfunction were detected, revision surgery entailed re-instrumentation with the PDDC implant. None of the cases were converted to a fusion procedure. 
Fig. 1 a 12-year old girl Lenke $158^{\circ}$, Risser grade 1 . T9 coronal wedging is $10^{\circ}$. b Immediate postoperative $\mathrm{x}$-ray. c At 2 years follow-up the curve measures $20^{\circ}$ and coronal wedging is $4^{\circ}$ (Risser 4 stage). In this case the device was anchored to the spine by two proximal pedicle screws via an "extender"
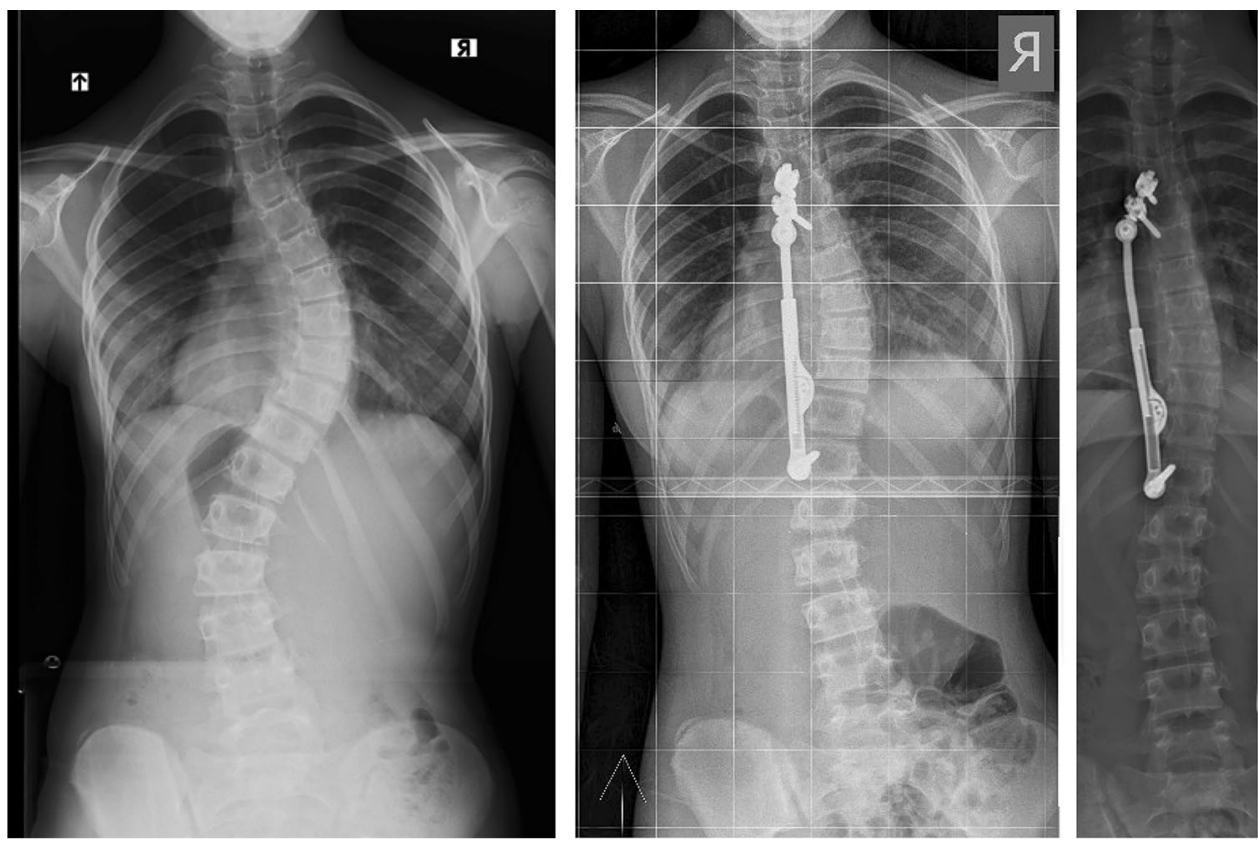

B
A
C
Table 1 Apical wedging in degrees

$\begin{array}{lll}\text { Preop. Apical } & \begin{array}{l}\text { Apical wedging } \\ \text { wedging (range) }\end{array} & \begin{array}{l}\text { at last follow-up wedging } \\ \text { (range) }\end{array}\end{array}$

\begin{tabular}{llll}
\hline All patients (45) & $7.4^{\circ}\left(3.8^{\circ}-15^{\circ}\right)$ & $\mathbf{5 . 7 ^ { \circ } *}\left(1^{\circ}-15^{\circ}\right)$ & $\mathbf{1 . 7}^{\circ *}$ \\
Risser 0-1 (16) & $9.5^{\circ}\left(6^{\circ}-14.5^{\circ}\right)$ & $\mathbf{5 . 4}^{\circ *}\left(1^{\circ}-8^{\circ}\right)$ & $\mathbf{4 . 1}^{\circ *}$ \\
Risser 2-3 (15) & $7.7^{\circ}\left(4^{\circ}-15^{\circ}\right)$ & $7.0^{\circ}\left(3^{\circ}-15^{\circ}\right)$ & $0.7^{\circ}$ \\
Risser 4-5 (14) & $4.8^{\circ}\left(3.8^{\circ}-6.5^{\circ}\right)$ & $4.7^{\circ}\left(3.7^{\circ}-6.5^{\circ}\right)$ & $0.1^{\circ}$ \\
\hline
\end{tabular}

*denotes $p<0.05$

\section{Discussion}

We retrospectively compared the outcomes of three groups of patients with moderate AIS that were instrumented with PDDC, each group had a different Risser sign grade and was in a different stage of skeletal maturity (Risser 0-1, 2-3 and $4-5)$ at the time of surgery.

The three groups were compared in regards to the magnitude of main curve reduction and the extent of remodeling in the coronal plane wedging of the apical vertebra following surgery with PDDC. Average preoperative major curve
Fig. 2 Delta coronal apical vertebra wedging between preoperative $\mathrm{x}$-ray and last follow-up x-ray plotted against the preoperative Risser sign

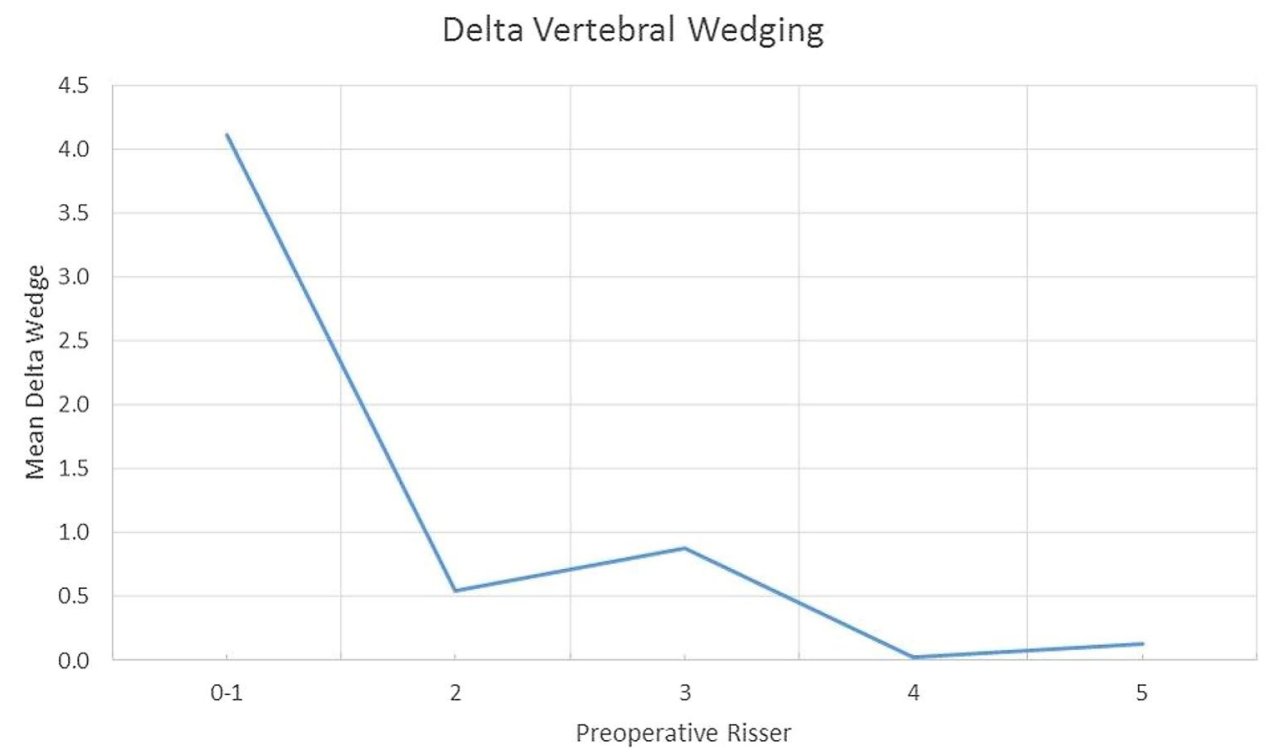


magnitude, of either Lenke 1 or 5 types, was similar among the three groups $47.6^{\circ}, 46^{\circ}$ and $41.5^{\circ}$. Curves were reduced to $26.4^{\circ}, 20.4^{\circ}$ and $26.2^{\circ}$, respectively, at final follow-up (average 2.3 years). Sagittal plane alignment was largely maintained with only slight but clinically insignificant increase in thoracic kyphosis in the Lenke 1 curves by $7^{\circ}$ and decrease in lumbar lordosis by $4^{\circ}$ in the Lenke 5 curves.

The main goal of this retrospective review was to evaluate the ability of the PDDC implant to act as a "true" internal brace and modulate spinal growth in AIS patients. It was found that the PDDC device enabled significant vertebral growth modulation as well as curve correction when applied in individuals who were at the early stages of skeletally maturation i.e. Risser $0-1$. The average pre-operative wedging of $9.5^{\circ}$ in the latter group, was significantly reduced to $5.4^{\circ}$ at final follow-up. The growth modulation achieved in this group was in accordance with the Hueter-Volkmann principle. In patients who were in more advanced stages pf skeletal maturity, PDDC growth modulation was negligible and insignificant (groups with Risser stages 2-3 or 4-5). In contrast, curve correction was similar among the three groups.

The Hueter-Volkmann principle describes the response of growing bones to applied compression forces [10]. Abnormal loading of the epiphyseal plate alters the "normal" growth pattern. In general, compression forces inhibit bone growth while distraction forces stimulate bone growth. For example, growth is retarded on the concave side of a scoliotic curve while on the convex side growth continues in a normal pace or is even stimulated. This asymmetrical spinal growth results in a wedge-shaped apical vertebra. The continuous asymmetric loading and asymmetric growth leads to curve progression resulting in a vicious cycle scenario [11].

The Hueter-Volkmann law has been implicated not only as the underling mechanism for scoliotic curve progression but also as the basis for bracing in scoliosis treatment. Braces are the main stay of non-operative treatment of progressing AIS curves in skeletally immature individuals. Application of a spinal brace in scoliotic individuals is an attempt to normalize physiologic mechanical loading conditions of the vertebral growth plate during the adolescent growth. It has been calculated, in a finite element model simulating a $26^{\circ}$ Lenke 1 curve, that there is an increase stress at the growth plate by $37 \%$ between the concave and convex sides of the apical vertebra [12]. By changing asymmetric growth of a spinal curve during the growth spurt, bracing slows down or stops curve progression. This is what is called vertebral remodeling.

The magnitude of the applied forces and the time of force application by the spinal brace are crucial in inducing vertebral remodeling. In an animal model of a spinal deformity, it was found that full time force application created twice the effect of growth modulation achieved with part time application $(24 \mathrm{~h}$ a day vs. $12 \mathrm{~h}$ ) [13]. A similar time dependent effect was found in adolescents with idiopathic scoliosis wearing a brace. A dose dependent effect was found, greater hours of brace wearing correlated with less or no curve progression [14].

Bracing is not always successful. Among the many factors associated with failed bracing, poor brace wear compliance is a leading cause for failure. From analysis of experimental and clinical data it is obvious that full compliance with the bracing regimen is crucial. An external brace is almost never worn for $24 \mathrm{~h}$ a day. The PDDC, an "internal brace" acts continuously, $24 \mathrm{~h}$ a day seven days a week. Thus, application of sustained mechanical forces will normalize asymmetric stress distribution and normalize vertebral growth with vertebral remodeling and sustained correction of the deformity. The current study lends support to the assumption that the PDDC device acts as a growth sparing implant that eliminates asymmetric loading of the vertebral growth plate and provides for long term correction and stabilization of the curvature.

A similar biomechanical effect favoring vertebral remodeling occurs with VBT. Newton et al. [1] have demonstrated that tethering was able to alter vertebral growth and correct scoliosis at 2-4 years after surgery. These investigators stated that the indications for the procedure were AIS patients with flexible $45^{\circ}-60^{\circ}$ curves and Risser $0-1$ [1]. The specified indications are almost identical to the indications for PDDC, AIS curves from $45^{\circ}-60^{\circ}$ demonstrating curve flexibility to $35^{\circ}$ on lateral bending views. On the other hand, Murray et al. [15] reported that VBS failed to differentially influence vertebral body growth.

In a significant portion of braced AIS patients, curve progression occurs despite proper bracing. It was found that bracing, even with full compliance, in Risser $0-1$ patients with curves exceeding $40^{\circ}$, was associated with very high percentage of bracing failure between 70 and 100\% [16]. Early intervention with the "internal brace" in such patients, before significant curve progression, would result in both immediate curve correction and better vertebral remodeling. Reducing the Cobb angle to lower values and smaller apical vertebral wedging by the PDDC device may allow future removal of the dynamic implant, after skeletal maturity, without the fear of recurrent curve progression.

The shortcomings of the current study are the small cohort, retrospective analysis, and the lumping together of Risser 0 and Risser 1 cases. An additional disadvantage of the current investigation is related to the measurement of the wedged apical vertebra. While the deformation of the apical wedge in scoliosis is three dimensional, we measured only the coronal wedge deformation. However, our measurements of apical vertebral wedging were similar to the measurements described in a finite element model of AIS [17]. Another aspect of curve morphology that was not evaluated in the present investigation was the shape of the intervertebral disc which is also affected by the altered mechanics in a spinal curvature.

In summary, this study provides support to the notion that the PDDC device can modulate growth in Risser 0-1 
AIS patients. In these patients, the PDDC device was able to correct vertebral wedging, by reducing asymmetrical loading of the vertebral growth centers, in addition to providing immediate and post-operative curve correction. The growth and motion sparing ability of the PDDC instrumentation may allow to recruit the remaining vertebral growth to arrest and correct the spinal deformity.

Author contributions All authors whose names appeared on the submission made substantial contributions to the conception or design of the work; or the acquisition, analysis, or interpretation of data; or the creation of new software used in the work; drafted the work or revised it critically for important intellectual content; approved the version to be published; and agree to be accountable for all aspects of the work in ensuring that questions related to the accuracy or integrity of any part of the work are appropriately investigated and resolved. YF: data collection, analysis of data, wrote the manuscript. REH: analysis of data, statics, editing of manuscript. BL: study design, analysis of data, editing of manuscript. RRB: analysis of data, editing of manuscript. UA: study design, data collection, and analysis of data.

Funding No funding was provided.

\section{Compliance with ethical standards}

Conflict of interest YF: Co-founder ApiFix. REH: Depuy Synthes Spine, Medtronic Canada, Wishbone Medical, Globus Medical, ApiFix Ltd, Joint Solutions Alliance. BL: DePuy Synthes to Setting Scoliosis Straight Foundation, OREF, ApiFix, DePuy Synthes, Zimmer Biomet. RRB: DePuy Synthes Spine, Globus Medical, SpineGuard, Thieme Medical Publishers; Speakers Bureau payments from DePuy Synthes Spine and Globus Medical; Consulting fees from ApiFix, DePuy Synthes Spine, Globus Medical, SpineGuard, and Wishbone Medical; and stock/options from Abyrx, ApiFix, Electrocore, Medovex, Orthobond, SpineGuard, and Wishbone Medical. UA: Founder ApiFix.

Ethical approval Ethics approval was waived by the local Ethics Committee in view of the retrospective nature of the study, and all procedures were part of routine care.

Open Access This article is licensed under a Creative Commons Attribution 4.0 International License, which permits use, sharing, adaptation, distribution and reproduction in any medium or format, as long as you give appropriate credit to the original author(s) and the source, provide a link to the Creative Commons licence, and indicate if changes were made. The images or other third party material in this article are included in the article's Creative Commons licence, unless indicated otherwise in a credit line to the material. If material is not included in the article's Creative Commons licence and your intended use is not permitted by statutory regulation or exceeds the permitted use, you will need to obtain permission directly from the copyright holder. To view a copy of this licence, visit http://creativecommons.org/licenses/by/4.0/.

\section{References}

1. Newton PO, Kluck DJ, Saito W et al (2018) Anterior Spinal growth tethering for skeletally immature patients with scoliosis. J Bone Joint Surg Am 100:1691-1697
2. Bonsignore-Opp L, Murphy J, Skaggs D et al (2019) Growth modulation for childhood scoliosis: from where have we come, and where are we going? J POSNA 1:1-8

3. Trupia A, Asu AC, Mueller JD, Matsumoto H, Bodenstein L, Vitale M (2019) Treatment of idiopathic scoliosis with vertebral body stapling. Spine Deformity 7:720-728

4. Wall EJ, Jain VV, Crawford AW, Bylski-Austrow D, Reynolds JE (2019) Spine growth modulation in early adolescent idiopathic scoliosis: prospective US FDA IDE pilot study of titanium clipscrew implant at two to five years. Spine Deformity 7:899-909

5. Floman Y, Burnei G, Gavriliu S, Anekstein Y, Straticiuc S, Tunyogi-Csapo M et al (2015) Surgical management of moderate adolescent idiopathic scoliosis with ApiFix ${ }^{\circledR}$ : a short peri-apical fixation followed by post-operative curve reduction with exercises. Scoliosis 10:4-9

6. Arnin U, El-Hawary R, Betz RR, Lonner BS, Floman Y (2019) Preclinical bench testing on a novel posterior dynamic scoliosis correction device for scoliosis. Spine Deformity 7:203-212

7. Floman Y, Gavriliu S, Potaczek T, Zarzycki D, Desai B, TunyogiCsapo M, et al (2018): A New posterior dynamic device for correction of moderate adolescent idiopathic scoliosis: 27 cases with two to five years of follow up. International Meeting on Advanced Spine Techniques (IMAST) Los Angeles Paper \#61 pg. 101-102 (abstract)

8. Floman Y, El Hawary R, Millgram MA, Lonner BS, Betz RR (2020) Surgical management of moderate AIS with a fusionless posterior dynamic deformity correction device: interim results with bridging 5-6 discs levels at 2 or more years of follow-up. $\mathbf{J}$ Neurosurg Spine 32:748-754

9. Floman Y, El-Hawary R, Lonner BS, Betz RR (2020): Vertebral growth modulation by posterior dynamic deformity correction device in skeletally immature patients with adolescent idiopathic scoliosis. International meeting on advanced Spine techniques (IMAST) Athens Paper \#176 (abstract)

10. Mehlman CT, Araghi A, Roy TR (1997) Hyphenated history: The Hueter-Volkmann Law. Am J Orthop 798-800

11. Stokes I, Spence H, Aronsson D, Kilmer N (1996) Mechanical modulation of vertebral body growth: implications for scoliosis progression. Spine 21:1161-1167

12. Driscoll M, Aubin CE, Moreau A, Parent S (2011) Biomechanical comparison of fusionless growth modulation corrective techniques in pediatric scoliosis. Med Biol Eng Comput 49:1437-1445

13. Stokes I, Aronsson D, Dimock A, Cortright V, Beck S (2006) Endochondral growth in growth plates of three species at two anatomical locations modulated by mechanical compression and tension. J Orthop Res 24(6):1327-1333

14. Katz DE, Herring A, Browne RH, Kelly DM, Birch JG (2010) Brace wear control of curve progression in adolescent idiopathic scoliosis. J Bone Joint Surg Am 92:1343-1352

15. Murray A, Tung R, Sherman A, Schwend RM (2020) Continued vertebral body growth in patients with juvenile idiopathic scoliosis following vertebral body stapling. Spine Deformity 8:221-228

16. El Hawary R, Zaaroor-Regev D, Floman Y, Lonner BS, Alkhalife YI, Betz RR (2019) Brace treatment in AIS: risk factors for failure - a literature review. The Spine J 19:1917-1925

17. Villemure I, Aubin C, Dansereau J, Labelle H (2002) Simulation of progressive deformities in adolescent idiopathic scoliosis using a biomechanical model integrating vertebral growth modulation. J Biomech Eng 124(6):p784-p790

Publisher's Note Springer Nature remains neutral with regard to jurisdictional claims in published maps and institutional affiliations. 